\title{
Identification of Crucial Residues in $\alpha$-Conotoxin EI Inhibiting Muscle Nicotinic Acetylcholine Receptor
}

\author{
Jiong Ning, Jie Ren, Yang Xiong, Yong Wu, Manqi Zhangsun, Dongting Zhangsun, \\ Xiaopeng Zhu *(i) and Sulan Luo *(i)
}

Key Laboratory of Tropical Biological Resources, Ministry of Education, Key Lab for Marine Drugs of Haikou, School of Life and Pharmaceutical Sciences, Hainan University, Haikou 570228, China;

ningjiong2018@163.com (J.N.); hndx2303@163.com (J.R.); ncdxxy@163.com (Y.X.); wuyong@hainu.edu.cn (Y.W.); zhangsunmanqi@163.com (M.Z.); zhangsundt@163.com (D.Z.)

* Correspondence: biozxp@163.com (X.Z.); luosulan2003@163.com (S.L.)

Received: 16 September 2019; Accepted: 8 October 2019; Published: 16 October 2019

check for updates

\begin{abstract}
Conotoxins ( $\alpha$-CTxs) are small disulfide-rich peptides from venom of Conus species that target nicotinic acetylcholine receptors (nAChRs). The muscle-type nAChRs have been recognized as a potential target for several diseases, such as myogenic disorders, muscle dystrophies, and myasthenia gravis. EI, an $\alpha 4 / 7-C T x$, mainly blocks $\alpha 1 \beta 1 \delta \varepsilon$ nAChRs and has an extra $\mathrm{N}$-terminal extension of three amino acids. In this study, the alanine scanning (Ala-scan) mutagenesis was applied in order to identify key residues of EI for binding with mouse $\alpha 1 \beta 1 \delta \varepsilon$ nAChR. The Ala-substituted analogues were tested for their abilities of modulating muscle and neuronal nAChRs in Xenopus laevis oocytes using two-electrode voltage clamp (TEVC) recordings. Electrophysiological results indicated that the vital residues for functional activity of EI were His-7, Pro-8, Met-12, and Pro-15. These changes exhibited a significant decrease in potency of EI against mouse $\alpha 1 \beta 1 \delta \varepsilon$ nAChR. Interestingly, replacing the critical serine (Ser) at position 13 with an alanine (Ala) residue resulted in a 2-fold increase in potency at the $\alpha 1 \beta 1 \delta \varepsilon \mathrm{nAChR}$, and showed loss of activity on $\alpha 3 \beta 2$ and $\alpha 3 \beta 4 \mathrm{nAChRs}$. Selectivity and potency of [S13A] EI was improved compared with wild-type EI (WT EI). In addition, the structure-activity relationship (SAR) of EI revealed that the "Arg1-Asn2-Hyp3" residues at the N-terminus conferred potency at the muscle-type nAChRs, and the deletion analogue ${ }^{\Delta 1-3}$ EI caused a total loss of activity at the $\alpha 1 \beta 1 \delta \varepsilon n A C h R$. Circular dichroism (CD) spectroscopy studies demonstrated that activity loss of truncated analogue ${ }^{\Delta 1-3} \mathrm{EI}$ for $\alpha 1 \beta 1 \delta \varepsilon \mathrm{nAChR}$ is attributed to disturbance of the secondary structure. In this report, an Ala-scan mutagenesis strategy is presented to identify crucial residues that are significantly affecting potency of $\mathrm{E} 1$ for mouse $\alpha 1 \beta 1 \delta \varepsilon \mathrm{nAChR}$. It may also be important in remodeling of some novel ligands for inhibiting muscle-type nAChRs.
\end{abstract}

Keywords: Muscle-type nAChR; $\alpha$-CTx EI; Ala-scan mutagenesis; TEVC; CD spectroscopy

Key Contribution: In this report, Ala-scan mutagenesis was applied to investigate the crucial residues in $\alpha$-Conotoxin EI for binding with mouse $\alpha 1 \beta 1 \delta 1 \varepsilon \mathrm{nAChR}$. A novel EI analogue [S13A] EI exhibited higher potency and selectivity for muscle type $\mathrm{nAChR}$ than other neuronal $\mathrm{nAChRs}$ subtypes compared to native EI. "Arg1-Asn2-Hyp3" residues at the N-terminus were key to contribution for binding the muscle nAChRs.

\section{Introduction}

Nicotinic acetylcholine receptors (nAChRs) are composed of five subunits that are arranged around a central cation pore, and they are a member of the ligand-gated ion channel superfamily [1-3]. The $\mathrm{nAChRs}$ are further classified into muscular and neuronal subtypes. The muscle-type receptors are 
mainly distributed at the skeletal neuromuscular junction and form heteropentamers composed of two $\alpha 1$, one $\beta 1$, one $\delta$, and one $\gamma / \varepsilon$ subunit [4,5]. Previous investigations demonstrated that muscle-type $\mathrm{nAChRs}$ are associated with pathophysiology conditions, including myogenic disorders, muscle dystrophies, and myasthenia gravis [6,7]. Several toxins that act specifically on muscle-type nAChR have entered the preclinical applications, including Azemiopsin (Az), a neuropeptide from the Azemiops feae viper venom. They are a high selectivity antagonist of muscle-type nAChR and are regarded with high potential for application to nondepolarizing muscle relaxants [8]. Another $\alpha$-bungarotoxin TFT, was discovered almost 50 years ago and has been widely used as a specific antagonist for neuro- and muscle-type nAChRs [9].

$\alpha$-Conotoxins ( $\alpha$-CTxs) show high affinities with muscle $n A C h R s$ and are small, disulfide-rich peptide toxins isolated from the venom of predatory marine snails (genus Conus), ranging typically from 12 to 20 amino acids in size [10,11]. These toxins block muscle-type and neuronal-type nAChRs with high potency and selectivity; for example, GIC selectively inhibited $\alpha 3 \beta 2 \mathrm{nAChR}$ with $\mathrm{IC}_{50}$ of $1.1 \mathrm{nM}$ [11]. $\alpha$-CTxs have been used as valuable tools in understanding the mechanism involved in ligand-receptor interaction for nearly 30 years [12,13]. $\alpha$-CTx EI is an 18-residue conotoxin, with a 4/7 intercysteine framework, isolated from the venom of Conus ermineus [14]. The sequence of EI is shown in Table 1. Unlike other neuronal selective $\alpha$-CTxs, EI has a three amino acid N-terminal tail and a post-modification hydroxyproline $(\mathrm{O})$ residue. EI potently inhibited $\alpha 1 \beta 1 \delta \varepsilon \mathrm{nAChR}$ with $\mathrm{IC}_{50}$ values of $187 \mathrm{nM}$ and is about 100 -fold less potent at $\alpha 3 \beta 2$ and $\alpha 3 \beta 4$ combinations [15,16]. Compared with other $\alpha 4 / 7-C T x s$, EI has an extra N-terminal tail and preference for muscle-type nAChRs versus neuronal-type nAChRs.

Table 1. Sequences of EI and its analogues.

\begin{tabular}{|c|c|c|c|}
\hline Peptide Number & Name & Sequences & \\
\hline 1 & EI & RDO CC YHPT C NMSNPQI C & * \\
\hline 2 & [R1A] EI & ADO $\mathrm{CC}$ YHPT $\mathrm{C}$ NMSNPQI $\mathbf{C}$ & * \\
\hline 3 & [D2A] EI & RAO CC YHPT $\mathbf{C}$ NMSNPQI $\mathbf{C}$ & * \\
\hline 4 & {$[\mathrm{O} 3 \mathrm{~A}] \mathrm{EI}$} & RDA $\mathbf{C C}$ YHPT $\mathbf{C}$ NMSNPQI $\mathbf{C}$ & * \\
\hline 5 & [Y6A] EI & RDO CC AHPT C NMSNPQI C & * \\
\hline 6 & [H7A] EI & RDO CC YAPT C NMSNPQI C & * \\
\hline 7 & [P8A] EI & RDO CC YHAT C NMSNPQI C & * \\
\hline 8 & [T9A] EI & RDO CC YHPA C NMSNPQI C & * \\
\hline 9 & {$[\mathrm{~N} 11 \mathrm{~A}] \mathrm{EI}$} & RDO CC YHPT C AMSNPQI C & ]* \\
\hline 10 & [M12A] EI & RDO CC YHPT C NASNPQI C & * \\
\hline 11 & [S13A] EI & RDO CC YHPT C NMANPQI C & * \\
\hline 12 & [N14A] EI & RDO $\mathrm{CC} Y \mathrm{YHPT} \mathrm{C}$ NMSAPQI $\mathrm{C}$ & J* \\
\hline 13 & {$[\mathrm{P} 15 \mathrm{~A}] \mathrm{EI}$} & RDO CC YHPT C NMSNAQI C & * \\
\hline 14 & [Q16A] EI & RDO CC YHPT C NMSNPAI C & * \\
\hline 15 & [I17A] EI & $\mathrm{RDO} \mathbf{C C}$ YHPT $\mathrm{C}$ NMSNPQA $\mathrm{C}$ & E* \\
\hline 16 & ${ }^{\Delta 1} \mathrm{EI}$ & DO CC YHPT C NMSNPQI $\mathbf{C}$ * & * \\
\hline 17 & $\triangle 1-2 \mathrm{EI}$ & O $\overline{\mathbf{C C}}$ YHPT $\overline{\mathbf{C}}$ NMSNPQI $\overline{\mathbf{C}}^{*}$ & * \\
\hline 18 & $\triangle 1-3 \mathrm{EI}$ & CC YHPT C NMSNPQI C * & \\
\hline
\end{tabular}

The framework of disulfide-bond Cys are characterized in boldface and boxed. Disulfide connectivity of $\alpha$-CTx EI and its analogues is between Cys1-Cys3 and Cys2-Cys4. Each substituted Alanine is labeled in bold and red. Asterisks denote a C-terminal amide. ${ }^{\Delta 1} \mathrm{EI},{ }^{\Delta 1-2} \mathrm{EI}$, and ${ }^{\Delta 1-3} \mathrm{EI}$ indicate truncating the N-terminus in $\alpha$-CTx EI sequentially by one residue, two residues, and three residues, respectively.

Previous studies have shown that the structure of EI was resolved by NMR and X-ray diffraction methods [16,17]. However, the role of each residue in $\alpha$-CTx EI remains partially unknown. The Ala-scan mutagenesis is a widely-used approach for exploring the structure-activity relationship (SAR) between receptors and ligands, and identifying key positions in protein that are important for function or 
ligand affinity [18]. In this report, EI and its analogues were synthesized and characterized (Table 1). Electrophysiological results indicate an N-terminal tail and a Ser-13 in $\alpha$-CTx EI that contribute to $\alpha 1 \beta 1 \delta \varepsilon$ nAChR potency and selectivity. A Pro in position 15 has obvious effects on potency of EI. Substitution of Ala for Pro-15 resulted in complete loss of activity compared with wild-type (WT) EI at both $\alpha 1 \beta 1 \delta \varepsilon$ nAChR and other neuronal nAChRs. In addition, the circular dichroism (CD) spectroscopy method was applied to further explore the secondary structure of EI and its analogues. The results of these studies provide valuable insight into the designing ligand that selectively targets muscle nAChRs.

\section{Results}

\subsection{Peptide Synthesis and Oxidative Folding of $\alpha$-Conotoxin EI and its Analogues}

For $\alpha$-CTx EI and its analogues, these linear peptides were successfully synthesized using standard solid phase peptide synthesis with Fmoc (9-fluorenylmethoxycarbonyl) chemistry. $\alpha$-CTxs have four cysteine residues with an $\mathrm{CC}-\mathrm{Xm}-\mathrm{C}-\mathrm{Xn}-\mathrm{C}$ framework that yields three possible disulfide bond connectivities: globular (I-III, II-IV), ribbon (I-IV, II-III), and beads (I-II, III-IV). Typically, the globular conformation occurred in natural $\alpha$-CTxs [19]. Acm-protected Cys residues were therefore incorporated at positions 2 and 4 in $\alpha$-CTx EI and analogues. The two-step oxidation is a widely-used approach for folding these peptides into the corresponding disulfide conformation. Briefly, the formation of first disulfide bond in each peptide incubated in $5 \mathrm{mM}$ ferricyanide $\left(\mathrm{pH} 7.5,2 \mathrm{mg} / \mathrm{mL}\right.$ ) $45 \mathrm{~min}$ at $25^{\circ} \mathrm{C}$. The monocyclic peptide was purified by preparative RP-HPLC. Closure of the second disulfide bond was treated with $0.4 \mathrm{mM} \mathrm{I}_{2}(0.4 \mathrm{mg} / \mathrm{mL})$ containing $1 \%$ TFA under nitrogen protection conditions for $10 \mathrm{~min}$. Then $1 \mathrm{M}$ ascorbic acid was gently added to terminate the reaction. The bicyclic product was again purified by preparative RP-HPLC. The fully oxidized peptide EI was detected by analytical RP-HPLC with the retention time of 12.31 min (Figure 1A), and ESI-MS of synthetic $\alpha$-CTx EI had an observed monoisotopic mass of $2092.82 \mathrm{Da}$, which was consistent with the theoretical molecular weight (2092.84 Da) (Figure 1B). Similarly, the observed molecular mass (2076.80 Da) of [S13A] EI was consistent with the theoretical molecular weight (2076.82 Da) (Figure 1C,D). A series of EI analogues were synthesized following the same protocol, and their HPLC chromatogram and mass spectrometry (MS) profiles are provided in the Supplementary Materials (Figures S1-S6). 
A

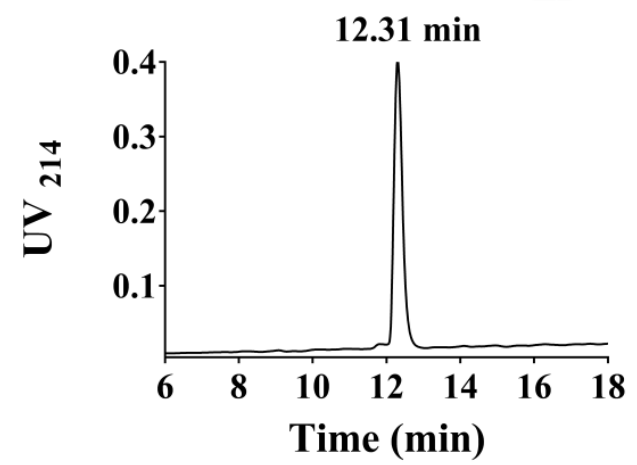

B

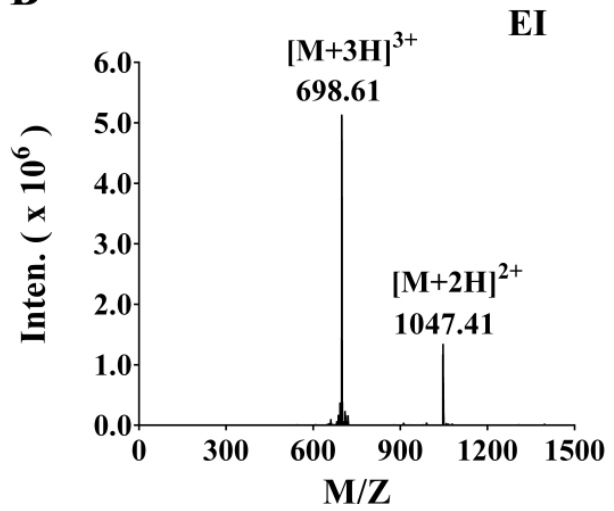

C

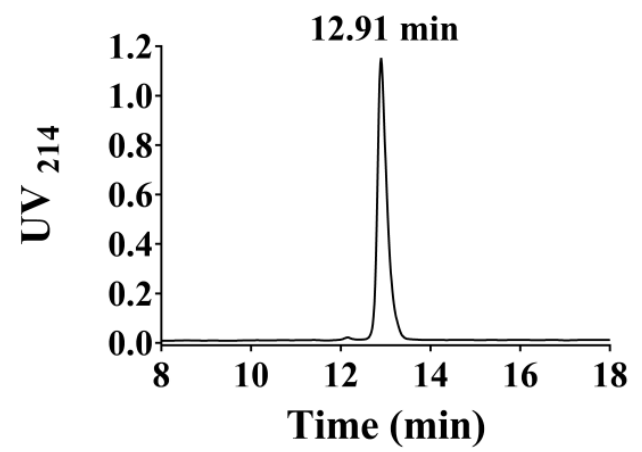

D

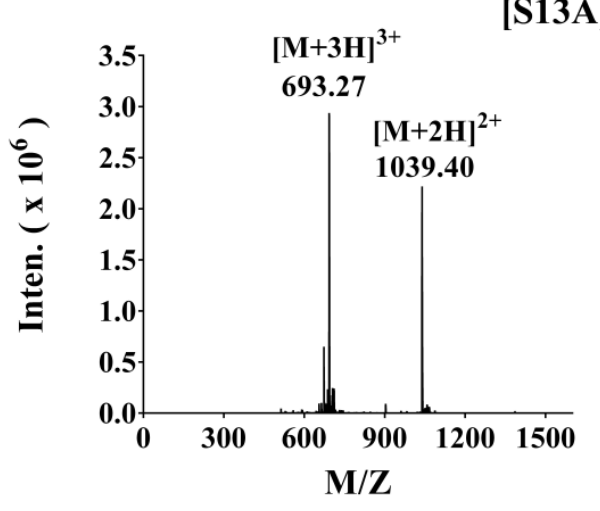

Figure 1. The HPLC and ESI-MS profiles of $\alpha$-CTx EI and [S13A] EI. The peptide EI was purified to a single compound using a reversed-phase analytical Vydac $\mathrm{C} 18$ column, eluted over a linear gradient $10-45 \%$ buffer $\mathrm{B}$ for $20 \mathrm{~min}$, where buffer $\mathrm{A}=0.075 \%$ TFA, remainder $\mathrm{H}_{2} \mathrm{O}$ and buffer $\mathrm{B}=0.050 \%$ TFA, 90\% acetonitrile, remainder $\mathrm{H}_{2} \mathrm{O}$. (A) HPLC chromatogram of fully oxidized and folded peptide EI. (B) A monoisotopic mass of 2092.82 Da (calculated 2092.84 Da) for EI was observed in the ESI-MS spectrum. (C) HPLC chromatogram of fully oxidized peptide [S13A] EI. (D) ESI-MS data for [S13A] EI with observed monoisotopic mass of 2076.80 Da (Calculated 2076.82 Da).

\subsection{Ala-SCAN of the Inter-Cysteine Loops Revealed Key Residues for EI Activity}

To better understand the SAR between $\alpha$-CTx EI and nAChRs, the Ala-substituted analogues were tested for the ability to modulate muscle and neuronal nAChRs in Xenopus laevis oocytes using two-electrode voltage clamp (TEVC) recordings. Figure 2 shows the relative amount of inhibition EI analogues generated comparing with WT EI at different concentrations. We observed that EI exhibited no activity at $\alpha 1 \beta 1 \delta \varepsilon \mathrm{nAChR}$ at the concentration of $10 \mathrm{nM}$, and it displayed only weak inhibition against muscle $\mathrm{nAChR}$ by incubation with $100 \mathrm{nM}$ EI (Figure 2A (I)). In contrast, with incubation of $100 \mathrm{nM}$ [S13A] EI, the inhibition of $\alpha 1 \beta 1 \delta \varepsilon$ nAChR current response to $10 \mu \mathrm{M}$ ACh was $80.4 \pm 2.5 \%$ $(n=3)$ (Figure 2A (II)). Concentration-response curves of EI and [S13A] EI were subsequently assessed on mouse $\alpha 1 \beta 1 \delta \varepsilon n A C h R$. Figure $3 C$ and Table 2 revealed that [S13A] EI inhibited $\alpha 1 \beta 1 \delta \varepsilon n A C h R$ with $\mathrm{IC}_{50}$ of $34.80 \mathrm{nM}$, a 2-fold higher potency than WT EI. High concentrations of [S13A] EI and EI were also tested at the $\alpha 3 \beta 2$ and $\alpha 3 \beta 4$ nAChRs; $1 \mu \mathrm{M}$ EI produced $52.5 \pm 3.2 \%(n=3)$ and $48 \pm 4.5 \%$ $(n=3)$ inhibition at the $\alpha 3 \beta 2$ and $\alpha 3 \beta 4 \mathrm{nAChRs}$, respectively (Figure $2 \mathrm{~B}(\mathrm{I})$ and $2 \mathrm{C}(\mathrm{I}))$. However, [S13A] EI showed different potency for both $\alpha 3 \beta 2$ and $\alpha 3 \beta 4 \mathrm{nAChR}$ subtypes. With incubation of 1 $\mu \mathrm{M}$ [S13A] EI, the inhibition of $\alpha 3 \beta 2$ and $\alpha 3 \beta 4 \mathrm{nAChRs}$ current response to $10 \mu \mathrm{M}$ ACh was $9.5 \pm 2.0 \%$ $(n=3)$ and $3 \pm 0.8 \%(n=3)$, respectively (Figure 2B (II) and 2C (II)). In conclusion, the selectivity of [S13A] EI was vastly improved at muscle and neuronal nAChRs versus WT EI. Replacing residue Tyr-6 with Ala or the substitution of Thr-9 with Ala all caused a decrease in potency at the $\alpha 1 \beta 1 \delta \varepsilon \mathrm{nAChR}$ but substantially exhibited an increase of potency for $\alpha 3 \beta 2$ and $\alpha 3 \beta 4 \mathrm{nAChR}$. [T9A] EI displayed 
an 11-fold and a 112-fold increase in activity at $\alpha 3 \beta 4$ and $\alpha 3 \beta 2 \mathrm{nAChR}$, respectively, compared with WT EI (Table 2). Most Ala mutants in $\alpha$-CTx EI exhibited a moderate decrease in antagonist activity for mouse $\alpha 1 \beta 1 \delta \varepsilon \mathrm{nAChR}$, including [R1A] EI, [N11A] EI, and [N14A] EI (Figure 3A,C). Figure 3 and Table 2 reveal that replacement of His-7, Pro-8, Met-12, or Pro-15 with Ala resulted in significant reductions in activity (Figure 3B,C), especially, [P15A] EI displayed a 190-fold decrease in potency at mouse $\alpha 1 \beta 1 \delta \varepsilon$ nAChR than native EI (Figure 3C). Four other mutants, [D2A] EI, [O3A] EI, [Q16A] EI, and [I17A] EI, preserved similar potency compared with WT EI (Figure 3A,C).

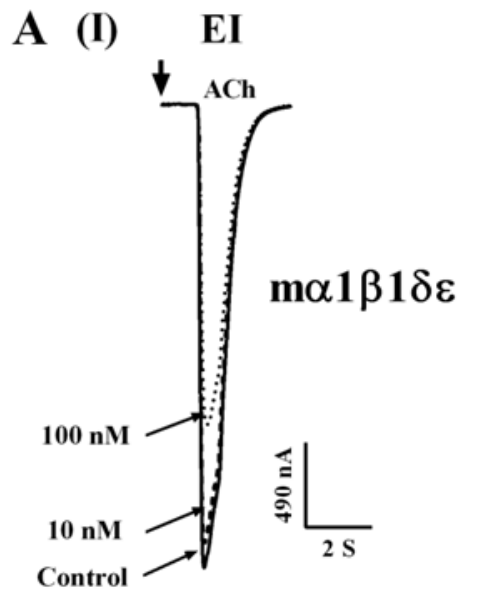

(II) $[\mathrm{S13A}] \mathrm{EI}$

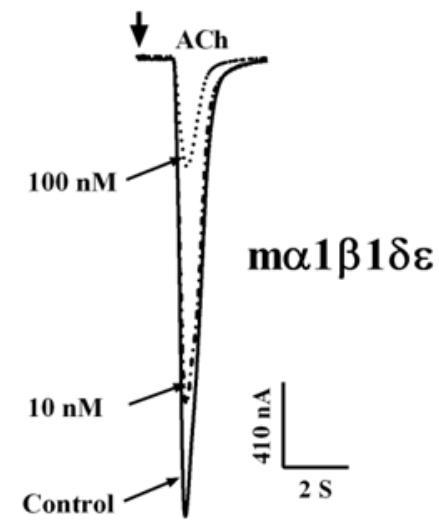

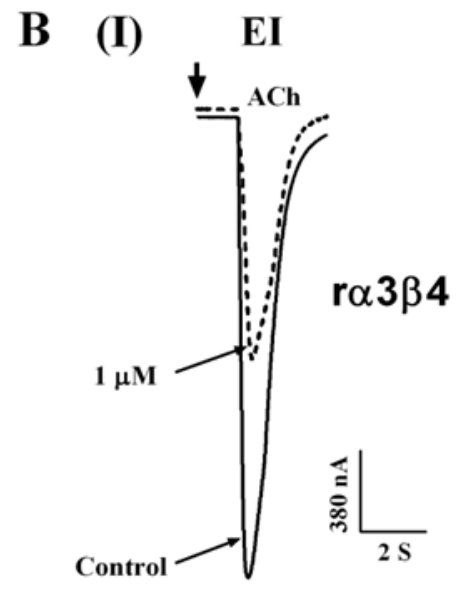

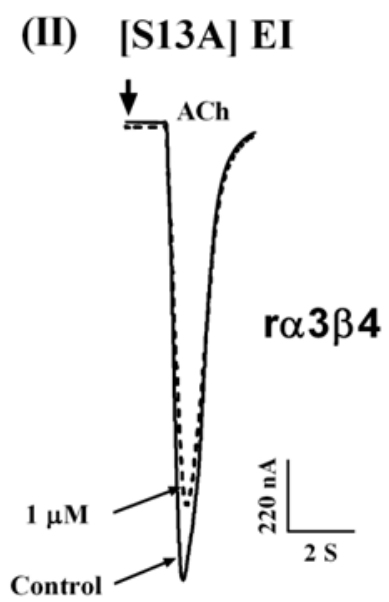

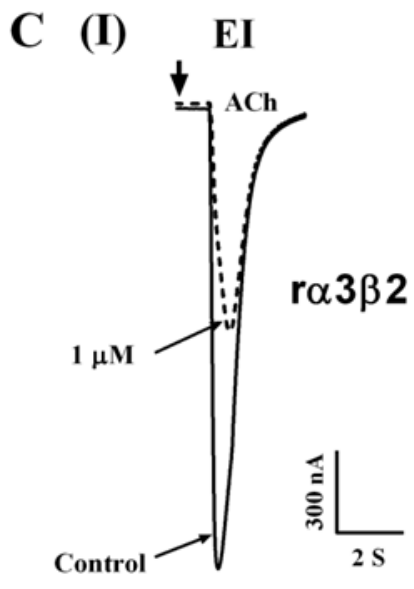

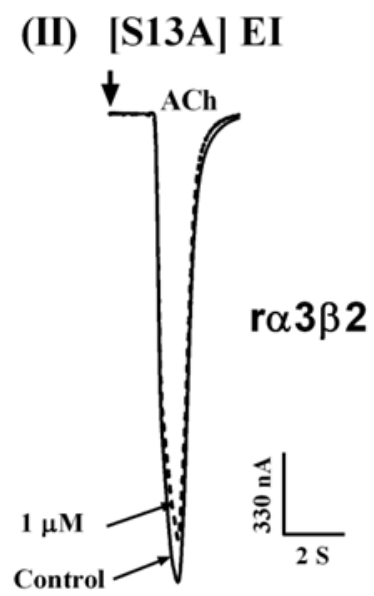

Figure 2. [S13A] EI inhibition of $\alpha 1 \beta 1 \delta \varepsilon, \alpha 3 \beta 2$, and $\alpha 3 \beta 4$ nicotinic acetylcholine receptors (nAChRs) compared with WT EI inhibition of these receptors. Cloned mouse $\alpha 1 \beta 1 \delta \varepsilon(\mathbf{A})$, rat $\alpha 3 \beta 4(\mathbf{B})$, rat $\alpha 3 \beta 2$ (C) nAChR subtypes heterologously expressed in Xenopus laevis oocytes were recorded by TEVC. Superimposed traces representative of ACh-evoked current inhibition of $\alpha 1 \beta 1 \delta \varepsilon(\mathbf{A}), \alpha 3 \beta 4(\mathbf{B})$, and $\alpha 3 \beta 2$ (C) nAChR subtypes by EI (I) and [S13A] EI (II). All data represent mean \pm S.E.M, $n=3-5$. 
A $\operatorname{mo1} \beta 1 \delta \varepsilon$

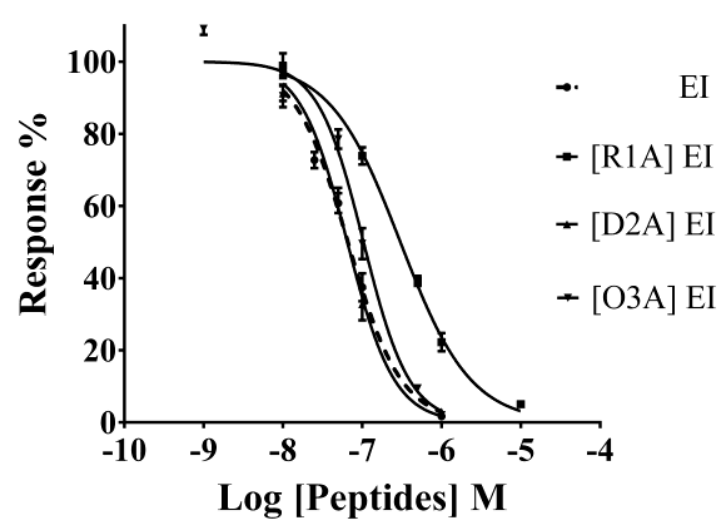

C $\operatorname{mo1} \beta 1 \delta \varepsilon$

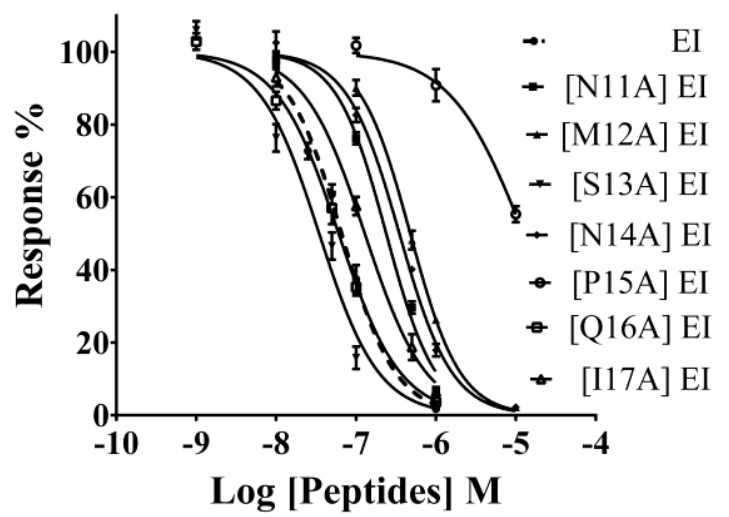

\section{B $m \alpha 1 \beta 1 \delta \varepsilon$}

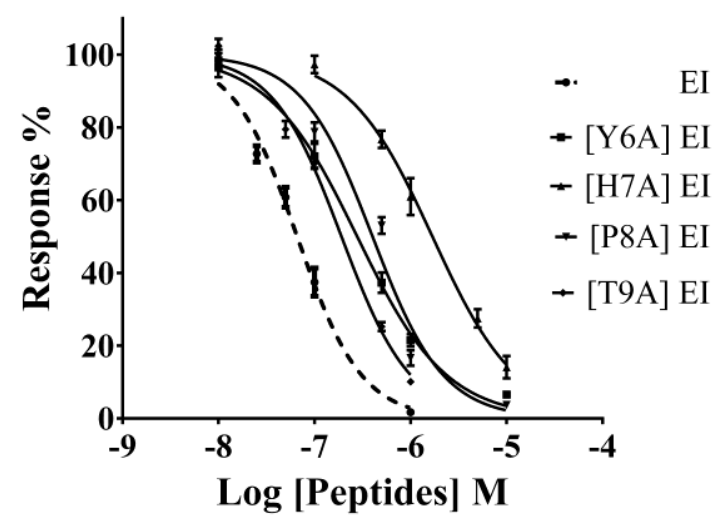

D $m \alpha 1 \beta 1 \delta \varepsilon$

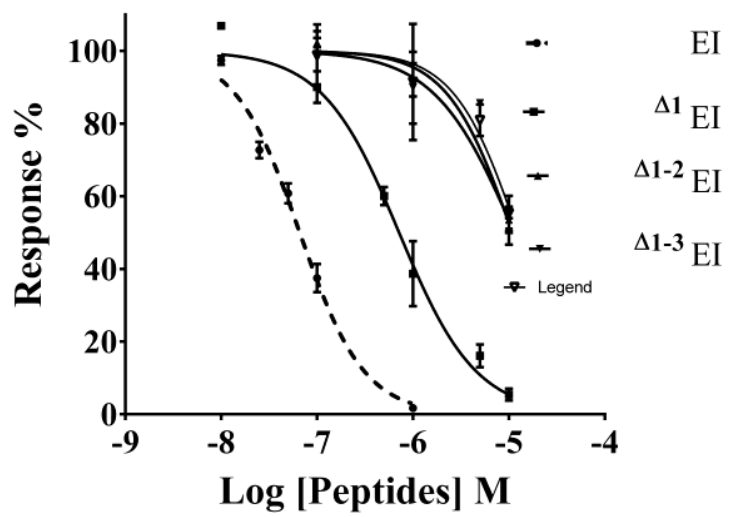

Figure 3. Effect of $\alpha$-CTx EI and analogues at the mouse $\alpha 1 \beta 1 \delta \varepsilon$ nAChR. (A) Concentration-response analysis for inhibition of mouse $\alpha 1 \beta 1 \delta \varepsilon$ nAChR by Ala-substituted analogues in N-terminal "tail" amino acids. (B) Concentration-response curves for the inhibitory of mouse $\alpha 1 \beta 1 \delta \varepsilon \mathrm{nAChR}$ by EI analogues with Ala substitutions in the loop1 region. (C) The inhibition of mouse $\alpha 1 \beta 1 \delta \varepsilon$ nAChR by EI analogues with Ala substitutions in the loop2 region was analyzed by concentration-response studies. (D) Concentration-response analysis for inhibition of mouse $\alpha 1 \beta 1 \delta \varepsilon$ nAChR by N-terminally truncated analogues in $\alpha$-CTx EI. All data represent mean \pm S.E.M., $n=6-8$. 
Table 2. The potencies of Ala-substituted $\alpha$-CTx EI and its analogues on muscle and neuronal nAChRs expressed in Xenopus laevis oocytes.

\begin{tabular}{|c|c|c|c|c|c|c|c|c|c|}
\hline \multirow[b]{2}{*}{ Peptides } & \multicolumn{3}{|c|}{$m \alpha 1 \beta 1 \delta \varepsilon$ nAChR } & \multicolumn{3}{|c|}{ r $\alpha 3 \beta 2 \mathrm{nAChR}$} & \multicolumn{3}{|c|}{ r $\alpha 3 \beta 4$ nAChR } \\
\hline & $\mathrm{IC}_{50}(\mathrm{nM})$ & $\mathrm{nH}$ & ${ }^{a}$ Ratio & $\mathrm{IC}_{50}(\mathrm{nM})$ & nH & ${ }^{a}$ Ratio & $\mathrm{IC}_{50}(\mathrm{nM})$ & nH & ${ }^{a}$ Ratio \\
\hline 1 & $65.9(58.5-74.2)$ & 1.3 & 1 & $7297(3748-14,200)$ & 0.8 & 1 & $6444(5443-7628)$ & 1.4 & 1 \\
\hline 2 & $302(265-346)$ & 1.0 & 4.6 & $>10,000$ & & & $>10,000$ & & \\
\hline 3 & $64.8(57.1-73.6)$ & 1.5 & 1.0 & $>10,000$ & & & $>10,000$ & & \\
\hline 4 & $104(91-119)$ & 1.5 & 1.6 & $>10,000$ & & & $>10,000$ & & \\
\hline 5 & $278(239-324)$ & 0.9 & 4.2 & $\sim 10,000$ & & & $547(435-687)$ & 1.1 & 0.08 \\
\hline 6 & 1688 (1407-2025) & 1.0 & 25.6 & $>10,000$ & & & $>10,000$ & & \\
\hline 7 & $401(338-477)$ & 1.2 & 6.1 & $>10,000$ & & & $>10,000$ & & \\
\hline 8 & $191(173-211)$ & 1.2 & 2.9 & $65.3(56.2-76.0)$ & 1.3 & 0.009 & $603(510-714)$ & 1.3 & 0.09 \\
\hline 9 & $239(213-268)$ & 1.4 & 3.6 & $>10,000$ & & & $>10,000$ & & \\
\hline 10 & $477(441-517)$ & 1.4 & 7.3 & $>10,000$ & & & $>10,000$ & & \\
\hline 11 & $34.6(28.2-42.4)$ & 1.2 & 0.5 & $>10,000$ & & & $>10,000$ & & \\
\hline 12 & $349(315-386)$ & 1.3 & 5.3 & $>10,000$ & & & $>10,000$ & & \\
\hline 13 & $12,510(9311-16,810)$ & 0.9 & 190 & $\sim 10,000$ & & & $>10,000$ & & \\
\hline 14 & $60.6(52.9-69.4)$ & 1.1 & 0.9 & $\sim 10,000$ & & & $>10,000$ & & \\
\hline 15 & $129(110-151)$ & 1.1 & 2.0 & $>10,000$ & & & $>10,000$ & & \\
\hline 16 & $716(566-907)$ & 1.1 & 11 & $>10,000$ & & & $>10,000$ & & \\
\hline 18 & $12,190(9394-15,810)$ & 1.3 & 185 & $>10,000$ & & & $>10,000$ & & \\
\hline
\end{tabular}

${ }^{\mathrm{a}}$ indicates EI analogues in the ratio of $\mathrm{IC}_{50}$ values relative to EI. $>1$ indicates a decrease in potency, whereas $<1$ indicates an increase in potency. $\mathrm{nH}$ indicates Hill slope. 


\subsection{N-Terminal Amino Acids in EI Influence the Activity of Peptide for $\alpha 1 \beta 1 \delta \varepsilon n A C h R$}

To measure the effect of N-terminal amino acids for mouse $\alpha 1 \beta 1 \delta \varepsilon$ nAChR, three N-truncated analogues were designed based on the number of N-terminal amino acids. Noticeably, two EI analogues, ${ }^{\Delta 1-2}$ EI and ${ }^{\Delta 1-3}$ EI, had a significant impact on potency for mouse $\alpha 1 \beta 1 \delta \varepsilon$ nAChR. Figure 4 reveals that ${ }^{\Delta 1-2}$ EI and ${ }^{\Delta 1-3}$ EI exhibited little effect on $\alpha 1 \beta 1 \delta \varepsilon$ nAChR at the concentration of $1 \mu \mathrm{M}$. These two analogues displayed no activity at other neuronal nAChRs including $\alpha 3 \beta 2$ and $\alpha 3 \beta 4$ $\mathrm{nAChRs}$, even at the concentrations up to $10 \mu \mathrm{M}$. Subsequently, the concentration-response curves for all three $\mathrm{N}$-truncated analogues are shown in the Figure $3 \mathrm{D}$ and the $\mathrm{IC}_{50}$ values of truncations at the N-terminus are summarized in Table 2. ${ }^{\Delta 1}$ EI inhibited the $\alpha 1 \beta 1 \delta \varepsilon$ nAChR with the $\mathrm{IC}_{50}$ of $716.4 \mathrm{nM}$ and the potency of ${ }^{\Delta 1}$ EI at the $\alpha 1 \beta 1 \delta \varepsilon$ nAChR was 11 -fold less than native EI. The activities of the other N-truncated analogues, including ${ }^{\triangle 1-2} \mathrm{EI}$ and ${ }^{\triangle 1-3} \mathrm{EI}$, whose potency for $\alpha 1 \beta 1 \delta \varepsilon \mathrm{nAChR}$ were 180 -fold lower than WT EI, and had an abolishment in $\alpha 3 \beta 2$ as well as $\alpha 3 \beta 4 \mathrm{nAChRs.} \mathrm{Above} \mathrm{all,}$ the fact demonstrated that the triple amino acids "RDO" at the N-terminus maintained crucially the potency of EI for mouse $\alpha 1 \beta 1 \delta \varepsilon$ nAChR.
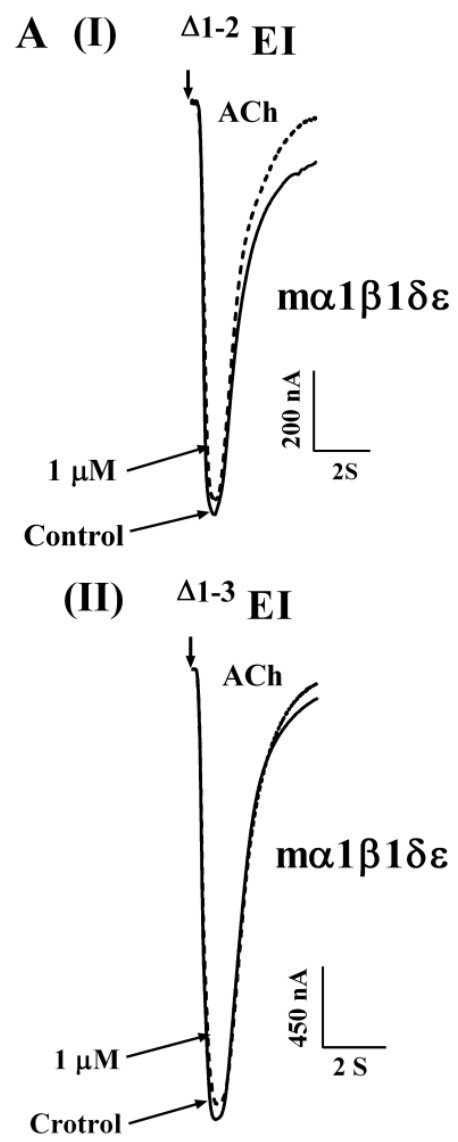
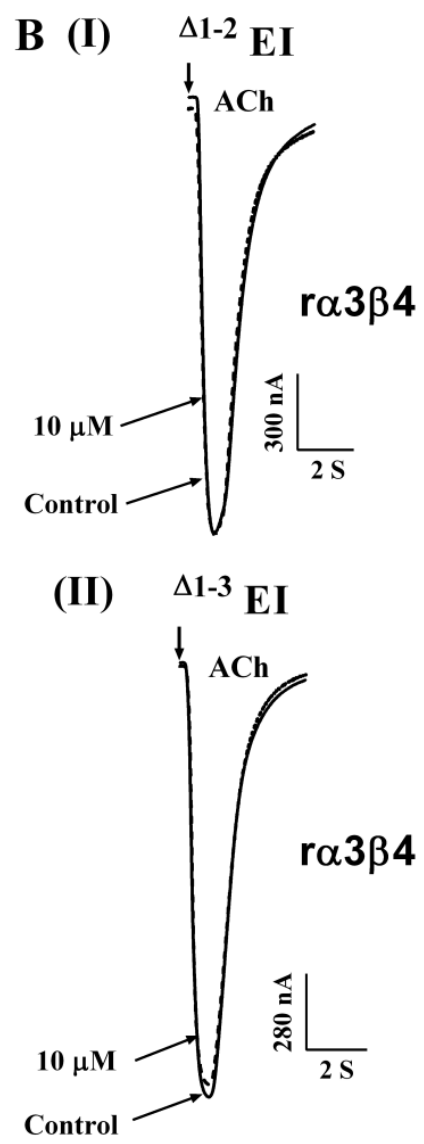
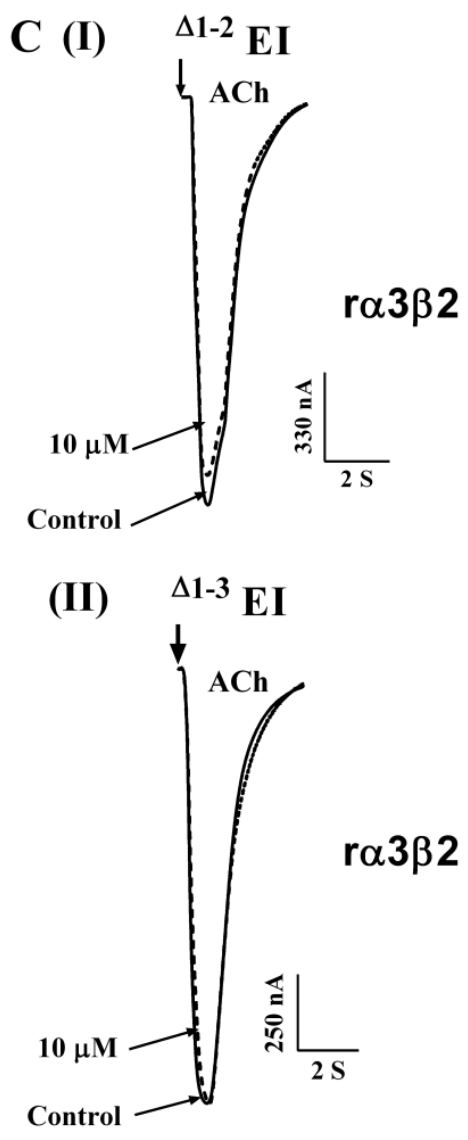

Figure 4. The effect on mouse $\alpha 1 \beta 1 \delta \varepsilon$ expressed in Xenopus laevis oocytes by N-terminal truncated analogues. Mouse $\alpha 1 \beta 1 \delta \varepsilon(\mathbf{A})$, rat $\alpha 3 \beta 4$ (B), rat $\alpha 3 \beta 2$ (C) nAChR subtypes expressed in Xenopus oocytes were activated by ACh. Superimposed traces representative of ACh-evoked current inhibition of $\alpha 1 \beta 1 \delta \varepsilon$ (A), $\alpha 3 \beta 4$ (B), and $\alpha 3 \beta 2$ (C) nAChR subtypes by ${ }^{\Delta 1-2} \mathrm{EI}$ (I) and ${ }^{\Delta 1-3} \mathrm{EI}$ (II). All data represent mean \pm S.E.M, $n=3-5$.

\subsection{Circular Dichroism Analysis}

CD spectra were obtained for aqueous solutions of native EI and their Ala-substituted analogues [P8A] EI, [S13A] EI, and [P15A] EI, as well as N-terminally truncated analogue ${ }^{\Delta 1-3}$ EI. Similar overall spectra were overlaid for [S13A] EI and EI with a positive ellipticity at $195 \mathrm{~nm}(\lambda)$, and two negative 
ellipticities at $208 \mathrm{~nm}(\lambda)$ and $222 \mathrm{~nm}(\lambda)$, respectively (Figure 5A). This indicated that these peptides were predominantly indicative of $\alpha$-helical. Replacement of Pro- 8 or Pro- 15 with Ala resulted in a remarkable change in spectral characteristic, and the other truncated analogue ${ }^{\Delta 1-3}$ EI gave CD spectra indicative of random coil structure as well (Figure 5B).

A

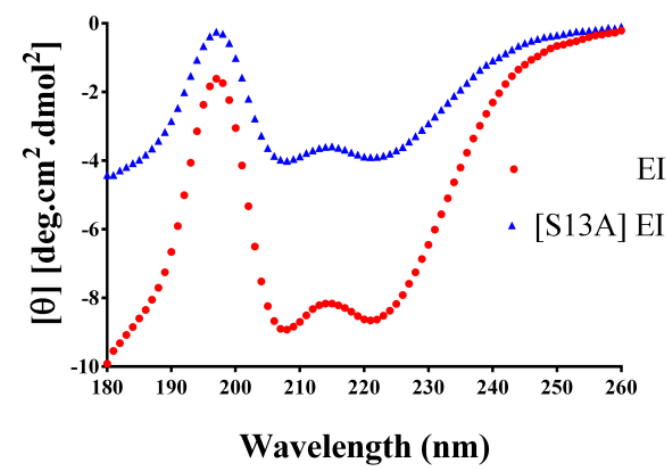

B

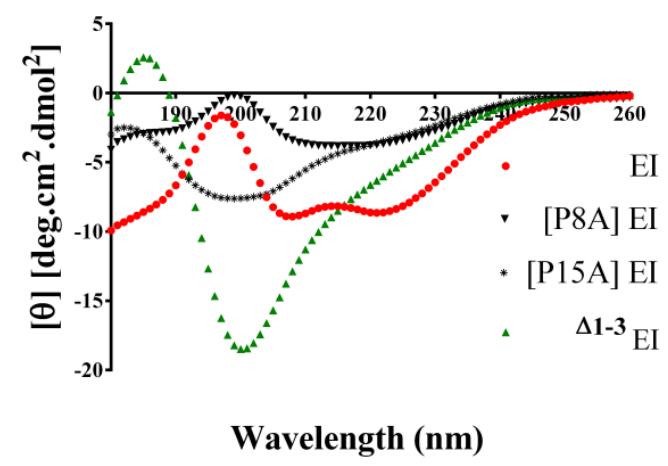

Figure 5. Characteristics of EI and its analogues. Circular dichroism (CD) spectra of Ala substitutions in the sequence of $\alpha$-CTx EI compared with native globular EI. (A). It revealed that [S13A] EI mutant had similar spectra to globular EI. (B). [P8A] EI, [P15A] EI, and ${ }^{\Delta 1-3}$ EI analogues do not display typically the $\alpha$-helix characteristic and exhibit just a positive peak, indicating their secondary structures are disrupted.

\section{Discussion}

So far, several toxins have been reported to block muscle-type nAChRs, and $\alpha$-CTxs are the most studied and pharmacologically characterized. It has been previously shown that $\alpha$-CTxs isolated from fish hunting cone snail venoms target mammalian and/or fish neuromuscular nAChRs, which generally consist of 3/5 framework; while $\alpha$-CTxs with a 4/7 loop motif primarily target mammalian neuronal nAChRs. However, $\alpha$-CTx EI is an exception, exhibiting muscle-type nAChR [11]. The $\alpha 3 / 5-C T x$ GI, $\mathrm{MI}$, and SI are amongst the first nicotinic antagonists from the cone snail venoms. They are antagonist of muscle type nAChRs with a high selectivity for muscle versus neuronal subtype nAChRs [20,21]. $\alpha 4 / 7-C T x s$ are widely used as nAChR antagonists, which are found in the venom of cone snails [22]. Table 3 summarizes some $\alpha 4 / 7-C T x$ that inhibited a variety of $n A C h R$ subtypes in the last fifteen years. For example, $\alpha 4 / 7-C T x$ RegIIA, which was isolated from the venom of Conus lividus, is an antagonist of $\alpha 3 \beta 2 \mathrm{nAChR}$ and it is also active at $\alpha 3 \beta 4$ and $\alpha 7 \mathrm{nAChRs}$, but has no activity at muscle-type nAChRs [23]. Another example, $\alpha 4 / 7-C T x$ GID, which was from Conus geographus, was isolated from crude venom using RP-HPLC. GID inhibits $\alpha 7$ and $\alpha 3 \beta 2 \mathrm{nAChRs}$ with $\mathrm{nM}$ affinity and exhibits at least 1000-fold less potency at muscle nAChR. Unlike other $\alpha 4 / 7-C T x s$, GID has N-terminal tail of four amino acids, two post-translationally modified residues, but lacks amidated C-terminus [24]. $\alpha 4 / 7-C T x$ $\mathrm{EI}$ is an exception, and preferentially targets $\alpha / \delta$ subunit interface versus $\alpha / \gamma$ in mammalian muscle nAChR [14]. In this study, a series of single point mutants of $\alpha$-CTx EI were synthesized and their potency was identified for $\alpha 1 \beta 1 \delta \varepsilon$ nAChR expressing in the Xenopus laevis oocytes. These analogues were also screened at other neuronal $n A C h R$ subtypes, such as $\alpha 3 \beta 2$ and $\alpha 3 \beta 4$. The identification of key residues in EI is vitally important to clarify the interaction mechanism with muscle-type, $\alpha 3 \beta 2$, and $\alpha 3 \beta 4$ nAChRs binding sites. 
Table 3. Known $\alpha 4 / 7-C T x$ s blocking various nAChR subtypes.

\begin{tabular}{|c|c|c|c|}
\hline$\alpha-\mathrm{CTx}$ & Sequences & Target & Reference \\
\hline EI & RDO CC YHPT C NMSNPQI C * & muscle, $\alpha 3 \beta 4, \alpha 3 \beta 2$ & [15] \\
\hline PIA & RDP CC SNPV C TVHNPQI C * & $\alpha 6 / \alpha 3 \beta 2 \beta 3, \alpha 6 / \alpha 3 \beta 4, \alpha 3 \beta 4, \alpha 3 \beta 2$ & [25] \\
\hline GID & IRD $\begin{array}{lll}\text { CC SNPA } & \text { C RVNNPHV C } \\
\end{array}$ & $\alpha 4 \beta 2, \alpha 3 \beta 2, \alpha 7$ & [24] \\
\hline LoIa & EG CC SNPA C RTNHPEV C D & $\alpha 7, \alpha 3 \beta 4$, muscle & [2] \\
\hline Mr1.7 & PE $\mathbf{C C}$ THPA $\mathbf{C}$ HVSHPEL $\mathbf{C}$ * & $\alpha 3 \beta 2, \alpha 9 \alpha 10$ & [26] \\
\hline RegIIA & G CC SHPA $\overline{\mathbf{C}}$ NVNNPHI $\overline{\mathbf{C}}$ * & $\alpha 3 \beta 4, \alpha 3 \beta 2, \alpha 7$ & [23] \\
\hline
\end{tabular}

The framework of disulfide-bond Cys are characterized in boldface and boxed. $\mathrm{O}$, hydroxyproline, and $\gamma$, $\gamma$-carboxyglutamic acid, and * indicates a C-terminal amide.

In this report, Ala-scan mutagenesis of $\alpha 4 / 7-\mathrm{CT}$ x EI was applied to examine the interaction between EI and $\alpha 1 \beta 1 \delta \varepsilon$ nAChR. Substitution of His-7, Pro-8, Met-12, and Pro-15 significantly reduced the potency of EI on $\alpha 1 \beta 1 \delta \varepsilon$ nAChR. Ala substitution of Arg-1, Asn-11, and Asn-14 led to a more than a 3-fold loss of activity at the $\alpha 1 \beta 1 \delta \varepsilon$ nAChR versus WT EI. Four mutants, [D2A] EI, [O3A] EI, [Q16A] EI, and [I17A] EI maintained the potency for $\alpha 1 \beta 1 \delta \varepsilon$ nAChR. Remarkably, substitution of residue Ser-13 with Ala increased the potency for $\alpha 1 \beta 1 \delta \varepsilon$ nAChR but nearly abolished activity for neuronal nAChR subtypes, and activity of [S13A] EI increased 2-fold at the $\alpha 1 \beta 1 \delta \varepsilon$ nAChR relative to native EI.

A conserved SHPA motif in loop1 region in $\alpha 4 / 7-C T x s$ is common and responsible for receptor binding activity [11,12]. The amino acids His and Pro in $\alpha$-CTxs loop1 are commonly thought to confer rigidity and stability to the $\alpha$-helical structure, and Pro in loop1 substituted by Ala completely abolished the activity of the main receptor. Previously study of $\alpha$-CTx GID, Millard et al. [27], revealed that replacing Pro in this region with Ala resulted in a total loss of the activity for $\alpha 4 \beta 2 \mathrm{nAChR}$. Similarly, Hone et al. [28], demonstrated that $\alpha$-CTx [P6A] PeIA mutant exhibited approximately 580-fold lower activity of $\alpha 3 \beta 2 \mathrm{nAChR}$ versus PeIA. However, in this study, when Pro was substituted with Ala in loop1, its potency for $\alpha 1 \beta 1 \delta \varepsilon n A C h R$ lowered 7-fold relative to native EI. It was found that substitution of Tyr- 6 and Thr-9 with Ala, respectively, had little effect on potency for $\alpha 1 \beta 1 \delta \varepsilon \mathrm{nAChR}$. Interestingly, the activity of [Y6A] EI and [T9A] EI dramatically increased at the neuronal nAChRs compared with WT EI, [T9A] EI mutant exhibited more than 10-fold potency for $\alpha 3 \beta 4 \mathrm{nAChR}$, and the activity of $\alpha 3 \beta 2$ nAChR increased greater than 100-fold compared with native EI. The reason why activity of [T9A] EI shifted from muscle $n A C h R$ to neuronal $n A C h R s$ is the difference between receptor subunits in extracellular region. The mechanism between [T9A] EI and $\alpha 3 \beta 2$ requires further elucidation.

It has been previously established that structural determinants in the first intracellular loop1 is primarily responsible for binding, and that a subset of residues in loop2 is of vital importance in subtype selectivity $[29,30] . \alpha$-CTx TxID, Wu et al. [31], revealed that Ser in the $9^{\text {th }}$ position substituted with Ala caused a 46-fold loss in potency for $\alpha 6 \beta 4 \mathrm{nAChR}$ and maintained the activity of $\alpha 3 \beta 4 \mathrm{nAChR}$, and selectivity of [S9A] TxID between $\alpha 6 \beta 4$ and $\alpha 3 \beta 4$ nAChR was improved versus native TxID. In this work, replacing residue Ser in loop2 led to little change of the potency for neuronal nAChRs but increased potency for $\alpha 1 \beta 1 \delta \varepsilon$ nAChR by 2-fold. Consequently, we can deduce that residues in loop2, especially Ser- 13 , had preferences for mouse $\alpha 1 \beta 1 \delta \varepsilon$ nAChR.

Previous studies have shown that most $\alpha 4 / 7-C T x$ mainly inhibited various neuronal nAChRs [2], whereas $\alpha 4 / 7-C T x$ EI mainly blocked muscle-type nAChRs with an unusual N-terminal tails. Several studies have revealed that the tails in the N-terminus in most $\alpha$-CTxs often play a pivotal role in binding receptors [12]. For instance, $\alpha$-CTx PIA mainly inhibited neuronal $\alpha 6 \beta 2 \mathrm{nAChR}$ with an extended Arg-Asn-Pro tail at the N-terminus and had the highest sequence homology with EI (Figure S7) [25]. Three truncated analogues, ${ }^{\Delta 1}$ PIA, ${ }^{\Delta 1-2}$ PIA, and ${ }^{\Delta 1-3}$ PIA, exhibited different affinities for $\alpha 6 \beta 2$ $\mathrm{nAChR}$ in competition binding studies [32]. Especially, ${ }^{\triangle 1-3}$ PIA significantly reduced affinity and potency for $\alpha 6 \beta 2 \mathrm{nAChR}$ comparing with native PIA. It was demonstrated that intrinsically disordered proteins (RDP) in solution but $\mathrm{N}$-terminus residues outside the cysteine framework in PIA form a stable $\beta 1$ secondary structure and yield biological functions [32]. A similar investigation was also 
performed on four residues at the N-terminus of $\alpha$-CTx GID (isoleucine, arginine, aspartic acid, and $\gamma$-carboxyglutamic acid) and deletion of the $\mathrm{N}$-terminal sequence resulted in inactivity for the main receptor $\alpha 4 \beta 2 \mathrm{nAChR}$ [27]. These results suggest that the IRD $\gamma$ region in GID can contribute to $\alpha 4 \beta 2$ nAChR activity (Figure S7) [24]. These results also indicate that the N-terminal extension in GID plays a crucial role in maintaining the $\alpha$-CTxs folding [27]. To further explore the role of $\mathrm{N}$-terminus in EI on the activity of EI at the $\alpha 1 \beta 1 \delta \varepsilon$ nAChR, a series of N-terminal truncations were also synthesized in the $\alpha$-CTx EI, and the activities of ${ }^{\Delta 1-2}$ EI and ${ }^{\Delta 1-3}$ EI analogues caused total loss of potency at the $\alpha 1 \beta 1 \delta \varepsilon$ $\mathrm{nAChR}$ in comparison to EI ${ }^{\mathrm{WT}}$. It can be therefore concluded that the $\mathrm{N}$-terminal residues, especially Hyp at the position 3 in the $\alpha$-CTx EI, play an important role in activity to muscle-type nAChR.

Two groups revealed the structure of EI using NMR spectroscopy and X-ray crystallography methods [14,17]. A typical structure of EI features was composed of two $\alpha$-helixes, Hyp3-Tyr6 and Pro8-Ser13, and a $\beta$-turn involving residues Asn14-Ile17. In this work, the secondary structure of native EI and its analogues were examined using circular dichroism spectroscopy and it was reported that three mutants were, [P8A] EI, [P15A] EI, and ${ }^{\Delta 1-3} \mathrm{EI}$, which are structurally different from native EI. It therefore was deduced that a change in secondary structure caused the loss in toxin potency. However, the structure of [S13A] EI resembled native EI; the increase in toxin potency might not damage the secondary structure but the increase in binding between [S13A] EI and $\alpha 1 \beta 1 \delta \varepsilon \mathrm{nAChR}$. The mechanism between [S13A] EI and muscle nAChR needs to be further elucidated.

In summary, we identified residues in EI crucial for interaction with muscle-type nAChRs. The aim was to help improve the design of EI analogues that selectively and potently target receptors involved with muscle-type nAChRs.

\section{Materials and Methods}

\subsection{Synthesis and Purification of EI and Analogues}

EI and its analogues were assembled on rink amide resin using solid-phase peptide synthesis (SPPS) with an ABI 433A peptide synthesizer (Applied Biosystem, Stafford, TX, USA) and a Fmoc (N-(9-fluorenyl) methoxycarbonyl) chemistry; the procedure was performed as previously described [33,34]. In brief, we protected the cysteine residues in pairs with either S-trityl (S-Trt) on Cys1 and Cys3, or S-acetamidomethyl (S-Acm) on Cys2 and Cys4. The resin was cleaved from peptides using reagent $\mathrm{K}$ (trifluoroacetic acid (TFA)/phenol/thioanisole/water/ethanedithiol; 90:7.5:5:5:2.5). The reaction solvent was evaporated and the remaining mixture in peptides was precipitated with ice-cold ether, then washed with ice-cold ether twice, finally filtered, dissolved in $60 \%$ buffer B $(60 \%$ $\mathrm{CH}_{3} \mathrm{CN}$ in $\mathrm{H}_{2} \mathrm{O}$ contain $0.05 \%$ TFA), and lyophilized. The peptide mixture was purified by RP-HPLC on a Vydac C18 column using a linear gradient of Buffer B ranging from 5 to $45 \%$ over $40 \mathrm{~min}$. The elution was monitored with UV detector monitored at $214 \mathrm{~nm}$. Buffer B was $90 \%$ acetonitrile (ACN) and $0.050 \%$ TFA in remainder $\mathrm{H}_{2} \mathrm{O}$ and buffer $\mathrm{A}$ was $0.075 \%$ TFA in remainder $\mathrm{H}_{2} \mathrm{O}$. The molecular mass of the fractions was confirmed by electrospray-mass spectroscopy (ESI-MS).

\section{2. $c R N A$ Preparation}

Plasmid DNAs that encoded various nAChR subunits were prepared as described previously [31]. These plasmids containing gene encoding mouse muscle-type $n A C h R$ subunits and rat neuro-type nAChR subunits were linearized by digestion with restriction enzymes Sma I (muscle-type nAChR), EcoR I ( $\mathrm{r} \alpha 3)$, Hind III $(\mathrm{r} \beta 2)$, and Xho I $(\mathrm{r} \beta 4)$. The $5^{\prime}$-terminal capped cRNAs were synthesized in vitro from there corresponding cDNA linearized templates using SP6, T7, and T3 mMESSAGE mMACHINE transcription Kit (Ambion, Austin, TX, USA). The cRNA was purified using MEGAclear ${ }^{\mathrm{Tm}}$ Transcription $^{2}$ Purification Kit (Ambion, Austin, TX, USA). Their concentration was confirmed by Smart Spec ${ }^{\mathrm{TM}}$ plus spectrophotometer (Bio-rad, Hercules, CA, USA), with their absorbance determined at 260 and $280 \mathrm{~nm}$. 


\subsection{Oocyte Isolation and Microinjection}

Oocytes (Stage V-VI) were prepared from mature female Xenopus laevis and digested with collagenase lasting for 40-60 min to remove follicle cells. Subsequently, the oocytes were incubated at $17^{\circ} \mathrm{C}$ in sterile ND96 buffer $(96.0 \mathrm{mM} \mathrm{NaCl}, 2.0 \mathrm{mM} \mathrm{KCl}, 1.8 \mathrm{mM} \mathrm{CaCl} 2,1.0 \mathrm{mM} \mathrm{MgCl} 2,5 \mathrm{mM} \mathrm{HEPES}$, $\mathrm{pH}$ 7.1-7.5), and supplemented with antibiotics $(10 \mu \mathrm{g} / \mathrm{mL}$ of streptomycin, $10 \mu \mathrm{g} / \mathrm{mL}$ of penicillin, and $100 \mu \mathrm{g} / \mathrm{mL}$ of gentamicin). Oocytes of mature were injected within $24 \mathrm{~h}$ of harvesting and cRNAs of various subunits were injected into each oocyte at a molar ratio of 1:1. Electrophysiological recordings were performed from $1-5$ days and incubated at $17^{\circ} \mathrm{C}$ after cRNA microinjection.

\subsection{Electrophysiological Recordings}

ACh induced membrane currents of whole oocyte cell were recorded 2-4 days after injection by using TEVC technique with an Axon 900A amplifier (Molecular Devices, Sunnyvale, CA, USA), and the holding potential $(\mathrm{Vm})$ of $\mathrm{nAChR}$ was clamped at $-70 \mathrm{mV}$. Electrodes were pulled from borosilicate glass, and this yielded a resistance between 0.5 and 2 megaohms $(\mathrm{M} \Omega)$ when supplementing with $3 \mathrm{M}$ $\mathrm{KCl}$. During recording, the oocyte chamber was a cylindrical well ( $\sim 50 \mu \mathrm{L}$ volume) and was perfused under gravity at a flow rate of $\sim 2 \mathrm{~mL} / \mathrm{min}$ with sterile ND96 solution (supplemented with $0.1 \mathrm{mg} / \mathrm{mL}$ BSA). The oocyte was subjected to 1-s ACh pulse every minute, the concentration of ACh treat with $\alpha 1 \beta 1 \delta \varepsilon, \alpha 3 \beta 2$, and $\alpha 3 \beta 4 \mathrm{nAChR}$ subtypes were $10 \mu \mathrm{M}, 100 \mu \mathrm{M}$, and $100 \mu \mathrm{M}$, respectively. Once a stable baseline current was recorded, either ND96 alone or ND96 containing various concentrations of EI and its analogues were perfusion-applied in a cylindrical well for $5 \mathrm{~min}$ before adding the agonist $\mathrm{ACh}$.

\subsection{Data Analysis}

In order to obtain a " $100 \%$ control" response before a test response, we used to normalize amplitude of the average of three recording. The concentration-response curves for EI and analogues were fitted by nonlinear regression analysis, $\%$ response $=100 /\left(1+\left([\operatorname{toxin}] / \mathrm{IC}_{50}\right)^{\mathrm{nH}}\right)$, where $\mathrm{nH}$ is the Hill slope, and $\mathrm{IC}_{50}$ indicates the inhibitory concentration of the antagonist required to produce $50 \%$ inhibition of the agonist response. All data represent mean \pm S.E.M. of at least three to eight independent experiments, which were statistically analyzed using Prism 6.0 software (GraphPad Software, San Diego, CA, USA).

\subsection{Circular Dichroism Spectroscopy}

CD spectra of EI and its analogues were tested on a Jasco J-815 spectropolarimeter with $10 \mathrm{~mm}$ path length quartz cuvette. EI analogues were dissolved in $20 \mathrm{mM}$ sodium phosphate buffer $(\mathrm{pH}$ 7.0) with the concentration of $43 \mu \mathrm{M}$. The spectra were measured in the far UV region (160-260 nm) using an average of 10 scans. The experimental parameters were set to a scanning speed of $50 \mathrm{~nm} / \mathrm{min}$, response time of $1 \mathrm{~s}$, sensitivity range of 100 millidegrees, and a step resolution of $1 \mathrm{~nm}$, and all the experiments were conducted in the temperature range of $17-23^{\circ} \mathrm{C}$, and the flow of nitrogen was maintained at $10 \mathrm{~mL} / \mathrm{min}$ for the duration of the measurements. The data were analyzed and processed using the Jasco system software.

Supplementary Materials: The following are available online at http://www.mdpi.com/2072-6651/11/10/603/s1, Figures S1-S5: HPLC chromatograms and mass spectrum of EI and alanine substituted analogues, Figure S6: HPLC chromatograms and mass spectrum of N-terminally truncated analogues in $\alpha$-CTx EI, Figure S7: The three-dimensional structure of EI (PDB: 1K64), PIA (PDB: 1ZLC), GID (PDB: 1MTQ).

Author Contributions: J.N., X.Z., and S.L. conceived and designed the experiments; J.N. and Y.X., M.Z. performed the experiments; J.R. and Y.W. verified this experiment; J.N., X.Z., J.R., Y.W., D.Z., and S.L. analyzed the data and prepared all figures; J.N., X.Z, Y.W., M.Z., and S.L. wrote the paper.

Acknowledgments: This research was funded by National Natural Science Foundation of China (No. 81872794, No. 31760249, and No. 81660585), Major International Joint Research Project of National Natural Science Foundation of China (81420108028), Hainan University Youth foundation (hdkyx201725), and Changjiang Scholars and Innovative Research Team in University Grant (IRT_15R15). 
Conflicts of Interest: The authors declare no conflict of interest.

\section{References}

1. Lewis, R.J.; Dutertre, S.; Vetter, I.; Christie, M.J. Conus venom peptide pharmacology. Pharmacol. Rev. 2012, 64, 259-298. [CrossRef] [PubMed]

2. Lebbe, E.K.; Peigneur, S.; Wijesekara, I.; Tytgat, J. Conotoxins targeting nicotinic acetylcholine receptors: An overview. Mar. Drugs 2014, 12, 2970-3004. [CrossRef] [PubMed]

3. Abraham, N.; Lewis, R.J. Neuronal Nicotinic Acetylcholine Receptor Modulators from Cone Snails. Mar. Drugs 2018, 16, 208. [CrossRef] [PubMed]

4. Albuquerque, E.X.; Pereira, E.F.; Alkondon, M.; Rogers, S.W. Mammalian nicotinic acetylcholine receptors: From structure to function. Physiol. Rev. 2009, 89, 73-120. [CrossRef]

5. Kalamida, D.; Poulas, K.; Avramopoulou, V.; Fostieri, E.; Lagoumintzis, G.; Lazaridis, K.; Sideri, A.; Zouridakis, M.; Tzartos, S.J. Muscle and neuronal nicotinic acetylcholine receptors. Structure, function and pathogenicity. FEBS J. 2007, 274, 3799-3845. [CrossRef]

6. Mott, M.; Luna, V.M.; Park, J.Y.; Downes, G.B.; Epley, K.; Ono, F. Expressing acetylcholine receptors after innervation suppresses spontaneous vesicle release and causes muscle fatigue. Sci. Rep. 2017, 7, 1674. [CrossRef]

7. Saxena, A.; Stevens, J.; Cetin, H.; Koneczny, I.; Webster, R.; Lazaridis, K.; Tzartos, S.; Vrolix, K.; Nogales-Gadea, G.; Machiels, B.; et al. Characterization of an anti-fetal AChR monoclonal antibody isolated from a myasthenia gravis patient. Sci. Rep. 2017, 7, 14426. [CrossRef]

8. Shelukhina, I.V.; Zhmak, M.N.; Lobanov, A.V.; Ivanov, I.A.; Garifulina, A.I.; Kravchenko, I.N.; Rasskazova, E.A.; Salmova, M.A.; Tukhovskaya, E.A.; Rykov, V.A.; et al. Azemiopsin, a Selective Peptide Antagonist of Muscle Nicotinic Acetylcholine Receptor: Preclinical Evaluation as a Local Muscle Relaxant. Toxins (Basel) 2018, 10, 34. [CrossRef]

9. Utkin, Y.N. Last decade update for three-finger toxins: Newly emerging structures and biological activities. World J. Biol. Chem. 2019, 10, 17-27. [CrossRef]

10. Muttenthaler, M.; Akondi, K.B.; Alewood, P.F. Structure-Activity Studies on Alpha-Conotoxins. Curr. Pharm. Des. 2011, 17, 4226-4241. [CrossRef]

11. Dutertre, S.; Nicke, A.; Tsetlin, V.I. Nicotinic acetylcholine receptor inhibitors derived from snake and snail venoms. Neuropharmacology 2017, 127, 196-223. [CrossRef] [PubMed]

12. Akondi, K.B.; Muttenthaler, M.; Dutertre, S.; Kaas, Q.; Craik, D.J.; Lewis, R.J.; Alewood, P.F. Discovery, synthesis, and structure-activity relationships of conotoxins. Chem. Rev. 2014, 114, 5815-5847. [CrossRef] [PubMed]

13. Olivera, B.M.; Rivier, J.; Clark, C.; Ramilo, C.A.; Corpuz, G.P.; Abogadie, F.C.; Mena, E.E.; Woodward, S.R.; Hillyard, D.R.; Cruz, L.J. Diversity of Conus Neuropeptides. Science 1990, 249, 257-263. [CrossRef] [PubMed]

14. Martinez, J.S.; Olivera, B.M.; Gray, W.R.; Craig, A.G.; Groebe, D.R.; Abramson, S.N.; McIntosh, J.M. $\alpha$-Conotoxin EI, a New Nicotinic Acetylcholine Receptor Antagonist with Novel Selectivity. Biochemistry 1995, 34, 14519-14526. [CrossRef] [PubMed]

15. Lopez-Vera, E.; Aguilar, M.B.; Schiavon, E.; Marinzi, C.; Ortiz, E.; Restano Cassulini, R.; Batista, C.V.; Possani, L.D.; Heimer de la Cotera, E.P.; Peri, F.; et al. Novel alpha-conotoxins from Conus spurius and the alpha-conotoxin EI share high-affinity potentiation and low-affinity inhibition of nicotinic acetylcholine receptors. FEBS J. 2007, 274, 3972-3985. [CrossRef] [PubMed]

16. Park, K.H.; Suk, J.E.; Jacobsen, R.; Gray, W.R.; McIntosh, J.M.; Han, K.H. Solution conformation of alpha-conotoxin EI, a neuromuscular toxin specific for the alpha 1/delta subunit interface of torpedo nicotinic acetylcholine receptor. J. Biol. Chem. 2001, 276, 49028-49033. [CrossRef] [PubMed]

17. Franco, A.; Marl, F. Three-dimensional structure of $\alpha$-conotoxin EI determined by ${ }^{1} \mathrm{H}$ NMR spectroscopy. Lett. Pept. Sci. 1999, 6, 199-207. [CrossRef]

18. Eustache, S.; Leprince, J.; Tuffery, P. Progress with peptide scanning to study structure-activity relationships: The implications for drug discovery. Expert Opin. Drug Dis. 2016, 11, 771-784. [CrossRef]

19. Janes, R.W. Alpha-Conotoxins as selective probes for nicotinic acetylcholine receptor subclasses. Curr. Opin. Pharmacol. 2005, 5, 280-292. [CrossRef] 
20. Jacobsen, R.B.; DelaCruz, R.G.; Grose, J.H.; Michael McIntosh, J.; Yoshikami, D.; Olivera, B.M. Critical Residues Influence the Affinity and Selectivity of $\alpha$-Conotoxin MI for Nicotinic Acetylcholine Receptors. Biochemistry 1999, 38, 13310-13315. [CrossRef]

21. Groebe, D.R.; Gray, W.R.; Abramson, S.N. Determinants Involved in the Affinity of $\alpha$-Conotoxins GI and SI for the Muscle Subtype of Nicotinic Acetylcholine Receptors. Biochemistry 1997, 36, 6469-6474. [CrossRef] [PubMed]

22. Nicke, A.; Wonnacott, S.; Lewis, R.J. Alpha-conotoxins as tools for the elucidation of structure and function of neuronal nicotinic acetylcholine receptor subtypes. Eur. J. Biochem. 2004, 271, 2305-2319. [CrossRef] [PubMed]

23. Franco, A.; Kompella, S.N.; Akondi, K.B.; Melaun, C.; Daly, N.L.; Luetje, C.W.; Alewood, P.F.; Craik, D.J.; Adams, D.J.; Mari, F. RegIIA: An alpha4/7-conotoxin from the venom of Conus regius that potently blocks alpha3beta4 nAChRs. Biochem. Pharmacol. 2012, 83, 419-426. [CrossRef] [PubMed]

24. Nicke, A.; Loughnan, M.L.; Millard, E.L.; Alewood, P.F.; Adams, D.J.; Daly, N.L.; Craik, D.J.; Lewis, R.J. Isolation, structure, and activity of GID, a novel alpha 4/7-conotoxin with an extended $\mathrm{N}$-terminal sequence. J. Biol. Chem. 2003, 278, 3137-3144. [CrossRef]

25. Dowell, C.; Olivera, B.M.; Garrett, J.E.; Staheli, S.T.; Watkins, M.; Kuryatov, A.; Yoshikami, D.; Lindstrom, J.M.; McIntosh, J.M. $\alpha$-Conotoxin PIA Is Selective for $\alpha 6$ Subunit-Containing Nicotinic Acetylcholine Receptors. J. Neurosci. 2003, 23, 8445-8452. [CrossRef] [PubMed]

26. Wang, S.; Zhao, C.; Liu, Z.; Wang, X.; Liu, N.; Du, W.; Dai, Q. Structural and Functional Characterization of a Novel alpha-Conotoxin Mr1.7 from Conus marmoreus Targeting Neuronal nAChR alpha3beta2, alpha9alpha10 and alpha6/alpha3beta2beta3 Subtypes. Mar. Drugs 2015, 13, 3259-3275. [CrossRef] [PubMed]

27. Millard, E.L.; Nevin, S.T.; Loughnan, M.L.; Nicke, A.; Clark, R.J.; Alewood, P.F.; Lewis, R.J.; Adams, D.J.; Craik, D.J.; Daly, N.L. Inhibition of neuronal nicotinic acetylcholine receptor subtypes by alpha-Conotoxin GID and analogues. J. Biol. Chem. 2009, 284, 4944-4951. [CrossRef]

28. Hone, A.J.; Ruiz, M.; Scadden, M.; Christensen, S.; Gajewiak, J.; Azam, L.; McIntosh, J.M. Positional scanning mutagenesis of alpha-conotoxin PeIA identifies critical residues that confer potency and selectivity for alpha6/alpha3beta2beta3 and alpha3beta2 nicotinic acetylcholine receptors. J. Biol. Chem. 2013, 288, 25428-25439. [CrossRef]

29. Clark, R.J.; Fischer, H.; Nevin, S.T.; Adams, D.J.; Craik, D.J. The synthesis, structural characterization, and receptor specificity of the alpha-conotoxin Vc1.1. J. Biol. Chem. 2006, 281, 23254-23263. [CrossRef]

30. Armishaw, C.; Jensen, A.A.; Balle, T.; Clark, R.J.; Harpsoe, K.; Skonberg, C.; Liljefors, T.; Stromgaard, K. Rational design of alpha-conotoxin analogues targeting alpha7 nicotinic acetylcholine receptors: Improved antagonistic activity by incorporation of proline derivatives. J. Biol. Chem. 2009, 284, 9498-9512. [CrossRef]

31. Wu, Y.; Zhangsun, D.; Zhu, X.; Kaas, Q.; Zhangsun, M.; Harvey, P.J.; Craik, D.J.; McIntosh, J.M.; Luo, S. alpha-Conotoxin [S9A]TxID Potently Discriminates between alpha3beta4 and alpha6/alpha3beta4 Nicotinic Acetylcholine Receptors. J. Med. Chem. 2017, 60, 5826-5833. [CrossRef] [PubMed]

32. Pucci, L.; Grazioso, G.; Dallanoce, C.; Rizzi, L.; De Micheli, C.; Clementi, F.; Bertrand, S.; Bertrand, D.; Longhi, R.; De Amici, M.; et al. Engineering of alpha-conotoxin MII-derived peptides with increased selectivity for native alpha6beta2* nicotinic acetylcholine receptors. FEBS J. 2011, 25, 3775-3789.

33. Gongora-Benitez, M.; Tulla-Puche, J.; Albericio, F. Handles for Fmoc solid-phase synthesis of protected peptides. ACS Comb. Sci. 2013, 15, 217-228. [CrossRef] [PubMed]

34. Luo, S.; Zhangsun, D.; Zhu, X.; Wu, Y.; Hu, Y.; Christensen, S.; Harvey, P.J.; Akcan, M.; Craik, D.J.; McIntosh, J.M. Characterization of a novel alpha-conotoxin TxID from Conus textile that potently blocks rat alpha3beta4 nicotinic acetylcholine receptors. J. Med. Chem. 2013, 56, 9655-9663. [CrossRef]

(C) 2019 by the authors. Licensee MDPI, Basel, Switzerland. This article is an open access article distributed under the terms and conditions of the Creative Commons Attribution (CC BY) license (http://creativecommons.org/licenses/by/4.0/). 